\title{
Antifungal Resistance Profile for Clinical Isolates of Candida spp. at Institute Pasteur of Côte d'Ivoire
}

Offianan $\mathrm{AT}^{1 *}$, Assi $\mathrm{SB}^{2}$, Koffi $\mathrm{D}^{1}$, Vanga-Bosson $\mathrm{H}^{1}$, Blavo-Kouamé $\mathrm{T}^{2}$, Kouadjo $\mathrm{F}^{1}$, Sylla $\mathrm{K}^{1}$ and Soumahrro $\mathrm{A}^{1}$

${ }^{1}$ Department of Parasitology\& Mycology, Mycology Unit, Institute Pasteur, Côte d'Ivoire

${ }^{2}$ Laboratory of Parasitology, Institute Pierre Richet Bouake, Côte d'Ivoire

*Corresponding author: Offianan Andre TOURE, Parasitology \& Mycology Department Institut Pasteur of Côte d'Ivoire, Tel: +225 05056367 37, Email: andre_offianan@yahoo.fr

\section{Research Aritcle \\ Volume 4 Issue 2}

Received Date: August 15, 2021

Published Date: September 06, 2021

DOI: $10.23880 /$ oajmms-16000145

\section{Abstract}

Background: The aim of this study was to identify Candida species isolated from clinical samples and detect their susceptibility patterns to antifungal agents.

Methodology: This study was conducted on clinical samples collected from patients with suspected candida infection referring to mycology laboratory of Institute Pasteur of Côte d'Ivoire for diagnosis. Candida species were isolated and identified using conventional and the innovative VITEK 2 microbial identification system. Antifungal susceptibility test for Amphotericin-B, 5-Flucytosine, Fluconazole, Itraconazole and Voriconazole were performed using ATB Fungus $3^{\circledR}$ of Biomerieux.

Results: Most of the isolates were obtained from vaginal swabs 806 (64.8\%), followed by Nail scrapings 49 (5.67\%). Overall C. albicans counting was $58.9 \%(732 / 1234)$ of the infections.

Sensitivity rates of C. albicans species from vaginal swab to 5-FC, AMB, FCZ, VCR and ITR were 97.26, 94.34, 94.89, 95.98 and 88.69 respectively. Resistance rates of $C$. albicans from vaginal swab were observed with AMB (5.66\%) and ITR (5.29\%). Sensitivity rate of $C$. glabrata was $100 \%$ with 5 -FC, AMB and VCR. All C.krusei species were resistant to fluconazole. The sensitivity rate of $C$. tropicalis to the antifungal drugs tested varied between $91.66 \%$ with ITR to 100 with VCR.

Conclusion: $C$. albicans was the most common of the candida species isolated in this study and remains sensitive to the drugs tested. The study showed resistance of all $C$. krusei strains to fluconazole. Knowledge about etiologic agents and their susceptibility patterns is helpful for successful treatment of the patients.

Keywords: Antifungal Susceptibility Testing; Antifungal Agents; Antifungal Resistance; Candida species

Abbreviations: 5-FC: 5-fluorocytosine; SC: SabouraudChloramphénicol; FCZ: Fluconazole; AMB: Amphotericin-B; SAC: Sabouraud-Actidione-Chloramphénicol; ITR: Itraconazole; VCR: Voriconazole.

\section{Introduction}

Candida species are ubiquitous yeasts that can cause a broad spectrum of human infections, known as candidiasis. 


\section{Open Access Journal of Mycology \& Mycological Sciences}

Candida albicans is by far the most common species. However, the increasing of non-albicans Candida (NAC) species have been recognized significantly during the last two decades [1]. The most NAC infections are caused by C. glabrata, C. tropicalis, C. parapsilosis, C. dubliniensis, C. guilliermondii, C. krusei, and C. kefyr [2-4]. Various antifungal drugs with different modes of action have been developed over the years. These include polyene antifungals (e.g. nystatin and amphotericin B), the imidazoles (e.g. miconazole, clotrimazole, econazole and ketoconazole), the echinocandins (e.g. anidulafungin, micafungin and caspofungin), the triazoles (including fluconazole, posaconazole, voriconazole and itraconazole) and the Fluoropyrimidines 5-fluorocytosine (5-FC). In the recent years, treatments of systemic candidiasis are a challenge due to resistant etiologic agents.

Resistance to available antifungal therapies is widespread probably due to the widespread and repeated use of these drugs. Different Candida species have varying resistance patterns, which appear to be geographically determined $[5,6]$. Antifungal resistance was generally uncommon; however, azole resistance occurs in several species, such as C. glabrata, C. tropicalis, and Candida krusei $[7,8]$.

C. albicans is by far the most common species causing infections in humans in Côte d'Ivoire [9,10]. Meanwhile, non-albicans Candida spp. were found to be emergent [11]. In Previous studies conducted at Abidjan C. albicans strains exhibited varying levels of resistance to 5-fluorocytosine, fluconazole, itraconazole, and voriconazole and amphotericin B $[10,12,13]$. Antifungal resistance is a major concern in clinical practice in Côte d'Ivoire. Azole antifungals such as fluconazole are often preferred treatment for many Candida infections as they are inexpensive, exhibit limited toxicity, and are available for oral administration [14]. The treatment is often carried out entirely on pragmatic basis, because fungal culture is not routinely taken, and susceptibility testing is scarcely done. Rapid species identification and antifungal susceptibility testing are essential for the treatment of candida infection in particular, as successful treatment of infections requires adequate information of the specific causative agent(s) and the drugs to which they are susceptible.

Antifungal resistance in the country reinforces the need to further study these pathogens and investigate susceptibility to drugs commonly used for treatment. Therefore National Surveillance Program to monitor antifungal resistance among yeasts and other pathogenic fungi in Côte d'Ivoire is increasingly important. This study was undertaken to assess antifungal susceptibility pattern of Candida isolates for an effective antifungal drug therapy for Candida infection.

\section{Methodology}

\section{Study Setting and Samples Collection}

This cross-sectional study was carried out on patients referred to the Mycology Laboratory of Institute Pasteur of Côte d'Ivoire for diagnosis of suspected fungal infection from January 2017 to April 2021. Informed consent to participate in this study was signed by all patients. Clinical samples including, vaginal discharge, nails, Squama and pus were collected and processed as per the standard microbiological procedures. Two vaginal swabs per patient were collected by the clinician from the posterior fornix of the vagina with sterile Dacron cotton swab stick after dilation using a sterile speculum. The tube containing the swab was labelled with the patients study number, initials and date and then transported into the Stuart transport medium, to the laboratory.

\section{Identification of Candida species}

The samples underwent a direct examination by wet mount preparation and Gram stain, inoculated on Sabouraud-Chloramphénicol (SC) and Sabouraud-ActidioneChloramphénicol (SAC) media. The inoculated media were incubated at $37^{\circ} \mathrm{C}$ for 24 to $48 \mathrm{~h}$; if no growth was observed, the incubation was extended up to $72 \mathrm{~h}$. Colonies were identified on the basis of their colour on chromogenic agar (Chromatic $^{\mathrm{TM}}$ Candida): C. albicans produces pale green colonies, C. tropicalis are blue-green, C. krusei are pink, and other species are white-pink.

\section{Yeast Identification}

All the yeast isolates were subjected to identification with the Vitek 2 compact system using Yeast card ID (VITEK 2 YST) as described by the manufacturer. Purity check on chromogenic medium was performed for all Vitek2 identifications. Quality control was achieved using C. parapsilosis ATCC 22019, C. albicans ATCC 611098, C. glabrata ATCC myA2950 and C. tropicalis ATCC 13803.

\section{Susceptibility Testing}

Antifungal susceptibility testing for Amphotericin-B (AMB), 5-Flucytosine (5-FC), Fluconazole (FCZ), Itraconazole (ITR) and Voriconazole (VCR) was performed using ATB Fungus $3 \circledR$ of Biomérieux as previously described $[12,15]$. Briefly ATB Fungus $3^{\circledR}$ of Biomérieux strip consists of 16 pairs of cupules including two growth control wells and five antifungal drugs at different concentrations: 5-Flucytosine (4, $16 \mu \mathrm{g} / \mathrm{ml}$ ), Amphotericin B ( 0.5 to $16 \mu \mathrm{g} / \mathrm{ml}$ ), Fluconazole (1 to $128 \mu \mathrm{g} / \mathrm{ml}$ ), Itraconazole ( 0.125 to $4 \mu \mathrm{g} / \mathrm{ml}$ ) and Voriconazole $(0.06$ to $8 \mu \mathrm{g} / \mathrm{ml})$. The inoculated strips were used in duplicate 
(c and C) and were read visually after incubation at $37^{\circ} \mathrm{C}$ for $24 \mathrm{~h}$. For each antifungal agent, the reading of the strips was started with the lowest concentration. The growth score was recorded for each of the wells and compared with the control wells as follows: No reduction in growth (4), slight reduction in growth (3), distinct reduction in growth (2), very weak growth (1) and no growth (0).

For Amphotericin B, the minimum inhibitory concentration (MIC) of the Candida species corresponded to its lowest concentration, thus enabling complete growth inhibition. For Fluconazole, Itraconazole and Voriconazole, as the possibility of a trailing growth existed; the MIC corresponded to the lowest concentration of the anti-fungal agent, with which a score of 2, 1 or 0 was obtained. For Flucytosine, a growth was looked for and was quantified in both the wells and tested for two concentrations. The results obtained gave an MIC that helps to classify the strain insensitive, intermediate or resistant. The anti-fungal breakpoints used followed the CLSI guidelines (National Committee for Clinical Laboratory Standards, 1997). Quality control was ensured by testing the CLSI-recommended quality control strains C. parapsilosis ATCC 22019 and C. krusei ATCC 6528 for both CLSI BMD and ATB FUNGUS 3 $[16,17]$.

\section{Ethical Considerations}

The study was conducted within the ethical standards and approved by the Comite National des Sciences de la Vie et de la Santé of Côte d'Ivoire. Written informed consent was obtained before any assessment was performed. If the patient was unable to read and write, then a witnessed consent was used. Patients $<18$ years old, who were capable of providing assent, provided assent in addition to parental/ legal guardian consent.

\section{Statistical Analysis}

All statistical analyses were performed using IBM SPSS software (version 22.0; IBM SPSS Inc., New York, USA). Categorical variables were compared using the $\chi 2$ or Fisher's exact test, and continuous variables by the Mann-Whitney $U$ test. A P value of 0.05 was considered significant.

\section{Results}

\section{Yeast Isolated}

Most of the isolates were obtained from vaginal swabs $806(64.8 \%)$, followed by Nail scrapings 49 (5.67\%). The other swabs (224) were taken fromsperm, oropharyngeal, sputum and stools. Overall C. albicans counting was $58.9 \%$ (732/1234) of the infections. C. glabrata, C. krusei and C. tropicalis were observed in a proportion of $1.20 \%, 6.4 \%$ and $4.8 \%$ respectively. Among the 806 vaginal yeast isolates, $C$. albicans was the most common species and identified in 548 $(68 \%)$ isolates, followed byC. krusei (4.8\%) (Table 1).

\begin{tabular}{|c|c|c|c|c|c|c|c|}
\hline \multirow{2}{*}{ Yeast Isolate } & \multicolumn{4}{|c|}{ Number (\%) of Yeast species Isolated from Sample Type } & \multirow{2}{*}{ Total } & \multirow{2}{*}{ p-values } \\
\cline { 2 - 7 } & VS & Squama & Nail scrapings & Pus & Others & & \\
\hline C. albicans & $548(67,99)$ & $8(18,60)$ & $28(31,82)$ & $29(35,36)$ & $119(53,12)$ & $732(58,89)$ & $<0,0001$ \\
\hline C. krusei & $39(4,84)$ & $10(23,25)$ & $12(13,63)$ & $3(3,66)$ & $16(7,14)$ & $80(6,43)$ & $<0,0001$ \\
\hline C. tropicalis & $24(2,97)$ & $7(16,28)$ & $6(6,82)$ & $5(6,09)$ & $17(7,59)$ & $59(4,75)$ & 0,0001 \\
\hline C. glabrata & $13(1,61)$ & 0 & 0 & 0 & $2(0,89)$ & $15(1,20)$ & 0,42 \\
\hline C. sp & $182(22,58)$ & $18(41,86)$ & $42(47,72)$ & $45(54,88)$ & $70(31,25)$ & $357(28,72)$ & $<0,0001$ \\
\hline Total & $806(100)$ & $43(100)$ & $88(100)$ & $82(100)$ & $224(100)$ & $1243(100)$ & - \\
\hline p-values & $<0,0001$ & $<0,0001$ & $<0,0001$ & $<0,0001$ & 0,2 & - & - \\
\hline
\end{tabular}

Table 1: Yeast species isolated from clinical sample tested.

\section{Antifungal Susceptibility Testing of Candida spp. Isolated from Vaginal Swab}

Susceptibility patterns of the common Candida species isolates from vaginal swab are shown in Table 2. Overall the sensitivity rates of Candida species from vaginal swab to 5-FC, AMB, FCZ, VCR and ITR were 95.04, 93.30, 89.83, 87.96 and 86.72 . 


\section{Open Access Journal of Mycology \& Mycological Sciences}

\begin{tabular}{|c|c|c|c|c|c|c|c|c|c|c|c|c|c|c|c|c|}
\hline \multirow{2}{*}{$\begin{array}{c}\text { Yeast species } \\
\text { Isolated }\end{array}$} & \multirow{2}{*}{$\begin{array}{c}\text { No of } \\
\text { Isolates }\end{array}$} & \multicolumn{3}{|c|}{ 5-FC } & \multicolumn{3}{|c|}{ AMB } & \multicolumn{3}{|c|}{ FCZ } & \multicolumn{3}{|c|}{ VCR } & \multicolumn{3}{|c|}{ ITR } \\
\hline & & $S$ & I & $\mathbf{R}$ & $S$ & I & $\mathbf{R}$ & $S$ & I & $\mathbf{R}$ & $S$ & I & $\mathbf{R}$ & $S$ & I & $\mathbf{R}$ \\
\hline C. al & 548 & $\begin{array}{c}533 \\
(97,26)\end{array}$ & $\begin{array}{c}8 \\
(1,46)\end{array}$ & $\begin{array}{c}7 \\
(1,28)\end{array}$ & $\begin{array}{c}517 \\
(94,34)\end{array}$ & 0 & $\begin{array}{c}31 \\
(5,66)\end{array}$ & $\begin{array}{c}520 \\
(94,89) \\
\end{array}$ & $\begin{array}{c}9 \\
(1,64)\end{array}$ & $\begin{array}{c}19 \\
(3,47)\end{array}$ & $\begin{array}{c}526 \\
(95,98)\end{array}$ & $\begin{array}{c}12 \\
(2,19)\end{array}$ & $\begin{array}{c}10 \\
(1,8)\end{array}$ & \begin{tabular}{|c|}
486 \\
$(88,69)$ \\
\end{tabular} & $\begin{array}{c}33 \\
(6,02) \\
\end{array}$ & $\begin{array}{c}29 \\
(5,29)\end{array}$ \\
\hline C. $g$ & 13 & $\begin{array}{c}13 \\
(100)\end{array}$ & 0 & 0 & $\begin{array}{c}13 \\
(100)\end{array}$ & 0 & 0 & $\begin{array}{c}9 \\
(69,23)\end{array}$ & 0 & $\begin{array}{c}4 \\
(30,77)\end{array}$ & $\begin{array}{c}13 \\
(100)\end{array}$ & 0 & 0 & $\begin{array}{c}12 \\
(92,3)\end{array}$ & $\begin{array}{c}1 \\
(7,69)\end{array}$ & 0 \\
\hline C. tro & 24 & $\begin{array}{c}23 \\
(95,83)\end{array}$ & $\begin{array}{c}1 \\
(4,17)\end{array}$ & 0 & $\left|\begin{array}{c}22 \\
(91,67)\end{array}\right|$ & 0 & $\begin{array}{c}2 \\
(8,33)\end{array}$ & $\begin{array}{c}23 \\
(95,83)\end{array}$ & 0 & $\begin{array}{c}1 \\
(4,17)\end{array}$ & $\begin{array}{c}24 \\
(100)\end{array}$ & 0 & 0 & $\left|\begin{array}{c}22 \\
(91,66)\end{array}\right|$ & $\begin{array}{c}1 \\
(4,17)\end{array}$ & $\begin{array}{c}1 \\
(4,17)\end{array}$ \\
\hline C. krusei & 39 & $\begin{array}{c}17 \\
(43,59)\end{array}$ & $\begin{array}{c}21 \\
(53,85)\end{array}$ & $\begin{array}{c}1 \\
(2,56)\end{array}$ & $\begin{array}{c}28 \\
(71,80)\end{array}$ & 0 & $\begin{array}{c}11 \\
(28,20)\end{array}$ & 0 & 0 & $\begin{array}{c}39 \\
(100)\end{array}$ & $\begin{array}{c}35 \\
(89,74)\end{array}$ & $\begin{array}{c}1 \\
(4,17)\end{array}$ & $\begin{array}{c}3 \\
(7,69)\end{array}$ & $\begin{array}{c}8 \\
(20,51)\end{array}$ & $\begin{array}{c}16 \\
(41,02)\end{array}$ & $\begin{array}{c}15 \\
(38,46)\end{array}$ \\
\hline C. $s p$ & 182 & $\begin{array}{c}180 \\
(98,90)\end{array}$ & $\begin{array}{c}2 \\
(1,10)\end{array}$ & 0 & $\begin{array}{c}172 \\
(94,50)\end{array}$ & 0 & $\begin{array}{c}10 \\
(5,5)\end{array}$ & $\begin{array}{c}172 \\
(94,50)\end{array}$ & $\begin{array}{c}6 \\
(3,3)\end{array}$ & $\begin{array}{c}4 \\
(2,20)\end{array}$ & $\begin{array}{c}111 \\
(60,99)\end{array}$ & $\begin{array}{c}44 \\
(24,17)\end{array}$ & $\begin{array}{c}27 \\
(14,84)\end{array}$ & $\left(\begin{array}{c}171 \\
(93,96)\end{array}\right.$ & $\begin{array}{c}5 \\
(2,75)\end{array}$ & $\begin{array}{c}6 \\
(3,29)\end{array}$ \\
\hline Tota & & 766 & 32 & 8 & 752 & 0 & 54 & 724 & 1 & 67 & 709 & 57 & 40 & 699 & 56 & 5 \\
\hline $\begin{array}{c}\% \\
\text { Susceptibility }\end{array}$ & & 95,04 & 3,97 & 0,99 & 93,30 & 0 & 6,7 & 89,83 & 1,86 & 8,31 & 87,96 & 7,07 & 4,97 & 86,72 & 6,95 & 6,33 \\
\hline $\mathrm{p}$-value & & $<0,00001$ & $<0,00001$ & $<0,00001$ & $<0,00001$ & & $<0,00001$ & $<0,00001$ & $<0,00001$ & $<0,00001$ & $<0,00001$ & $<0,00001$ & $<0,00001$ & $<0,00001$ & $<0,00001$ & $1<0,000$ \\
\hline
\end{tabular}

Table 2: Antifungal Susceptibility of isolates from Vaginal Swabs.

This sensitivity rates with $C$. albicans species to $5-\mathrm{FC}$, AMB, FCZ, VCR and ITR were 97.26, 94.34, 94.89, 95.98 and 88.69 respectively. High resistance rates of C. albicans were observed with AMB (5.66\%) and ITR (5.29\%). Sensitivity rate of C. glabrata was $100 \%$ with 5-FC, AMB and VCR. All C. krusei species from vaginal swab were resistant to fluconazole. The resistance rate of C. krusei to 5-FC, AMB, FCZ, and ITR was $2.56,28.20,7.69$ and 38.46 respectively.

The sensitivity rate of $C$. tropicalis to the antifungal drugs tested varied between $91.66 \%$ with ITR to 100 with VCR.

\section{Antifungal Susceptibility Testing of Candida spp. Isolated from other Samples}

Overall the sensitivity rates of Candida species from other samples to 5-FC, AMB, FCZ, VCR and ITR 98.02\%, $92.08 \%, 78.22 \%, 96.04 \%$ and $83.17 \%$.

Antifungal susceptibility of Candida species isolates from others samples are shown in Table 3.

\begin{tabular}{|c|c|c|c|c|c|c|c|c|c|c|c|c|c|c|c|c|}
\hline \multirow{2}{*}{\begin{tabular}{|c|} 
Yeast species \\
Isolated
\end{tabular}} & \multirow{2}{*}{$\begin{array}{c}\text { No of } \\
\text { Isolates }\end{array}$} & \multicolumn{3}{|c|}{ 5-FC } & \multicolumn{3}{|c|}{ AMB } & \multicolumn{3}{|c|}{ FCZ } & \multicolumn{3}{|c|}{ VCR } & \multicolumn{3}{|c|}{ ITR } \\
\hline & & $\mathbf{S}$ & I & $\mathbf{R}$ & $\mathbf{S}$ & I & $\mathbf{R}$ & $\mathbf{S}$ & I & $\mathbf{R}$ & $S$ & I & $\mathbf{R}$ & $\mathbf{S}$ & I & $\mathbf{R}$ \\
\hline C. albicans & 63 & $\begin{array}{c}61 \\
(96,82)\end{array}$ & $\begin{array}{c}1 \\
(1,59)\end{array}$ & $\begin{array}{c}1 \\
(1,59)\end{array}$ & $\begin{array}{c}61 \\
96,83)\end{array}$ & $\begin{array}{c}0 \\
(0)\end{array}$ & $\begin{array}{c}2 \\
(3,17)\end{array}$ & \begin{tabular}{|c|}
61 \\
$(96,83)$
\end{tabular} & \begin{tabular}{|c|}
2 \\
$3,17)$ \\
\end{tabular} & $\begin{array}{c}0 \\
(0)\end{array}$ & $\begin{array}{c}62 \\
(98,41)\end{array}$ & $0(0)$ & $\begin{array}{c}1 \\
(1,59)\end{array}$ & \begin{tabular}{|c|}
55 \\
$(87,30)$
\end{tabular} & $\begin{array}{c}6 \\
(9,52)\end{array}$ & $\begin{array}{c}2 \\
(3,17)\end{array}$ \\
\hline C. parapsilosis & 1 & $\begin{array}{c}1 \\
(100) \\
\end{array}$ & $0(0)$ & $0(0)$ & $\begin{array}{c}1 \\
(100) \\
\end{array}$ & \begin{tabular}{|c|}
0 \\
$(0)$ \\
\end{tabular} & $0(0)$ & $1(100)$ & $0(0)$ & $\begin{array}{c}0 \\
(0)\end{array}$ & $\begin{array}{c}1 \\
(100)\end{array}$ & $0(0)$ & $0(0)$ & $\begin{array}{c}1 \\
(100)\end{array}$ & $0(0)$ & $0(0)$ \\
\hline C. tropicalis & 18 & $\begin{array}{c}18 \\
(100)\end{array}$ & $0(0)$ & $0(0)$ & $\begin{array}{c}14 \\
(77,78)\end{array}$ & $\begin{array}{c}0 \\
(0)\end{array}$ & $\begin{array}{c}4 \\
(22,22)\end{array}$ & $\left|\begin{array}{c}17 \\
(94,45)\end{array}\right|$ & $\left|\begin{array}{c}1 \\
5,55)\end{array}\right|$ & $\begin{array}{c}0 \\
(0)\end{array}$ & $\begin{array}{c}17 \\
(94,45)\end{array}$ & $0(0)$ & $\begin{array}{c}1 \\
(5,55)\end{array}$ & $\begin{array}{c}14 \\
(77,78)\end{array}$ & $\begin{array}{c}2 \\
(11,11)\end{array}$ & $\begin{array}{c}2 \\
(11,11)\end{array}$ \\
\hline C. krusei & 19 & $\begin{array}{c}19 \\
(100)\end{array}$ & $\begin{array}{c}0 \\
(0)\end{array}$ & $0(0)$ & $\begin{array}{c}17 \\
(89,47)\end{array}$ & $\begin{array}{c}0 \\
(0)\end{array}$ & $\begin{array}{c}2 \\
(10,53)\end{array}$ & $0(0)$ & $0(0)$ & $\begin{array}{c}19 \\
(100)\end{array}$ & $\begin{array}{c}17 \\
(89,47)\end{array}$ & $\begin{array}{c}2 \\
(10,53)\end{array}$ & $0(0)$ & $\begin{array}{c}14 \\
(73,68) \\
\end{array}$ & \begin{tabular}{|c|}
2 \\
$10,53)$ \\
\end{tabular} & $\begin{array}{c}3 \\
(15,79)\end{array}$ \\
\hline Total & & 99 & 1 & 1 & 93 & 0 & 8 & 79 & 3 & 19 & 97 & 2 & 2 & 84 & 10 & 7 \\
\hline $\begin{array}{c}\% \\
\text { Susceptibility }\end{array}$ & & $\begin{array}{l}98, \\
02\end{array}$ & 0,99 & 0,99 & 92,08 & 0 & 7,92 & 78,22 & 2,97 & 18,81 & 96,04 & 1,98 & 1,98 & 83,17 & 9,90 & 6,93 \\
\hline $\mathrm{p}$-value & & $<0,00001$ & $<0,39$ & $<0,39$ & $<0,00001$ & - & 0,26 & $<0,00001$ & 0,29 & $<0,00001$ & $<0,00001$ & 0,11 & 0,57 & $<0,00001$ & 0,05 & 0,43 \\
\hline
\end{tabular}

Table 3: ATF Susceptibility Others samples. 


\section{Open Access Journal of Mycology \& Mycological Sciences}

The sensitivity rates with $\mathrm{C}$. albicans species to $5-\mathrm{FC}$, AMB, FCZ, VCR and ITR were respectively 96.82\%, 96.83\%, $96.83 \%, 98.41 \%$ and $87.30 \%$. C. albicans resistance rate was $3.17 \%$ with both AMB and ITR. All C. krusei species were resistant to $\mathrm{FCZ}$ while all were sensible to 5 -FC.

\section{Discussion}

Candida identification to species level is rarely made, and patients are treated empirically based on their clinical symptoms. The introduction of antifungal susceptibility testing before treatment initiation can be relatively expensive, but is certainly a long-term cost effective solution in preventing the progression of drug resistance. Increasing resistance to antifungal agents has been described and contributes to the difficulty in treating these infections. Hence, rapid yeast identification and susceptibility testing methods are required to optimize patient management. Most of the isolates in this study were obtained from vaginal swabs 806 (64.8\%) and C. albicans was the most Candida species isolated in this study following by $C$. krusei and C. tropicalis. Previous studies conducted in the country demonstrated also the predominance of $\mathrm{C}$. albicans among candida species $[9,12,13]$. Similar reports have been reported in previous studies [18-20]. The data in different parts of the world have recorded higher rates of $C$. albicans [21-24], while lower rates were also reported [25-28].

Among non-albicans Candida; C. krusei was the most common species isolated in our study followed by $C$. tropicalis. The predominance of $C$. albicans could be explained by its considerable ability to adhere to host constituents, as well as by its ability to modify its behavior according to the environment and the secretion of lytic enzymes, which involves specific ligand/receptor interactions with mannoproteins of the yeast wall $[29,30]$.

Our results showed that $C$. albicans species isolated from vaginal swab was susceptible to 5-FC, AMB, FCZ, VCR and ITR. Similar results were obtained with $C$. albicans from others samples. In this study resistance of $C$. albicans to fluconazole, voriconazole and itraconazole was respectively 3.47\%, 1.8\% and $5.29 \%$. These results are in contrast with results from others studies conducted in the country. According to a study carried out in Abidjan in 2017, C. albicans accounted for $64.8 \%$ of isolated strains of vaginal origin with rates of resistance of $26.3 \%$ for fluconazole, $27.7 \%$ for voriconazole and 39.7\% for itraconazole [13]. Djohan V, et al. [9] found in their study conducted in 2008 in Abidjan, a C. albicans resistance rate of $2.2 \%, 11.1 \%$ and $22.2 \%$ respectively to fluconazole, voriconazole and itraconazole.

It seems that the strains of $C$. albicans have become more sensitive to these fluconazole, voriconazole and Itraconazole during the last years in view of our results. This could be due to a drop in drug pressure as a result of better use of these drugs.

The most commonly prescribed antifungal used for most $C$. albicans infections is fluconazole, a member of the azole class of antifungals [31]. Fluconazole is widely used in public health settings in the country and is used empirically in the treatment candida infection, as it is less toxic and regarded as more effective than imidazole antifungals, such as ketoconazole or amphotericin B [32]. In this study resistance rate of $C$. albicans isolate from vaginal swab to fluconazole was $3.47 \%$ less than those observed in others studies. Resistance to azole antifungals in Candida has been most extensively studied in C.albicans. One mechanism of resistance identified in this species is the Presence of point mutations in ERG11 [33].

In our study $5.66 \%$ of $C$. albicans strains from vaginal swab were resistant to AMB (5.66\%) while no resistance was seen in others studies from Ivory Coast $[9,13]$ and elsewhere [34]. C. albicans resistance to amphotericin B has also been reported in Africa [32,35].

All C. krusei species from vaginal swab and others samples were resistant to fluconazole and resistance to others drugs was high. $C$. krusei resistance has been reported from elsewhere [32,36,37].

C. krusei possesses intrinsic resistance to fluconazole while also rapidly developing acquired resistance to other antifungal drugs. The mechanisms of antifungal resistance of this yeast involve the alteration and over expression of drug target, reduction in intracellular drug concentration and development of a bypass pathway [14].

The study has some limitations. Firstly, risk factors for candida infection such as pregnancy, antibiotic therapy, uncontrolled diabetes mellitus, immunosuppression due to HIV and others were not assessed. Secondly, the study was limited to a single Laboratory reference and thus, the results may not be applicable to other settings. Despite the limitations, the study provided baseline information on the identification of Candida species and their antifungal susceptibility in a reference laboratory in Côte d'Ivoire. The study demonstrated the fact that most antifungals continue to be active against Candida strains from Côte d'Ivoire.

\section{Conclusion}

C. albicans was the most common species associated with candida infections followed by $C$. krusei and C. albicans was susceptible to antifungal drugs tested in this study and all C. krusei strains were resistant to fluconanazole. Knowledge 


\section{Open Access Journal of Mycology \& Mycological Sciences}

of Candida species distribution and antifungal resistance pattern of them plays an important role in appropriate therapy.

\section{Statements \& Declarations}

Not applicable

\section{Funding}

The work was supported by Institute Pasteur of Cote d'Ivoire

\section{Competing Interests}

The authors declare no competing interests.

\section{References}

1. Enwuru CA, Ogunledun A, Idika N, Enwuru NV, Ogbonna F, et al. (2008) Fluconazole resistant opportunistic oropharyngeal Candida and non-Candida yeast-like isolates from HIV infected patients attending ARV clinics in Lagos. Nigeria Afr Health Sci 8(3): 142-148.

2. Pfaller MA, Castanheira M, Messer SA, Jones RN (2015) In vitro antifungal susceptibilities of isolates of Candida spp. and Aspergillus spp. from China to nine systemically active antifungal agents: data from the SENTRY antifungal surveillance program, 2010 through 2012. Mycoses 58(4): 209-214.

3. Pfaller M, Rhomberg P, Messer S, Jones R, Castanheira $M$ (2015) Isavuconazole, micafungin, and 8 comparator antifungal agents' susceptibility profiles for common and uncommon opportunistic fungi collected in 2013: temporal analysis of antifungal drug resistance using CLSI species-specific clinical breakpoints and proposed epidemiological cutoff values. Diagn Microbiol Infect Dis 82(4): 303-313.

4. Kołaczkowska A, Kołaczkowski M (2016) Drug resistance mechanisms and their regulation in non-albicans Candida species. J Antimicrob Chemother 71(6): 14381450.

5. Ksiezopolska E, Gabaldón T (2018) Evolutionary Emergence of Drug Resistance in Candida Opportunistic Pathogens. Genes 9(9): 461.

6. Arastehfar A, Gabaldón T, Garcia Rubio R, Jenks JD, Hoenigl M, et al. (2020) Drug-Resistant Fungi: An Emerging Challenge Threatening Our Limited Antifungal Armamentarium. Antibiotics (Basel) 9(12): 877.

7. Wiederhold NP (2017) Antifungal resistance: current trends and future strategies to combat. Infect Drug
Resist 10: 249-259.

8. Farmakiotisa D, Kontoyiannis DP (2017) Epidemiology of antifungal resistance in human pathogenic yeasts: current viewpoint and practical recommendations for management. Int J Antimicrob Agents 50 (3): 318-324

9. Djohan V, Angora KE, Vanga-Bosson AH, Konaté A, Kassi FK, et al. (2011) Sensibilité in vitro des souches de Candida albicans d'origine vaginale aux antifongiques à Abidjan (Côte d'Ivoire). J Mycol Med 22(2): 129-133.

10. Konate A, Yavo W, Kassi FK, Djohan V, Angora EK, et al. (2014) Aetiologies and contributing factors of vulvovaginal candidiasis in Abidjan (Cote d'Ivoire). J Mycol Med 24(2): 93-99.

11. Bonouman-Ira V, Angora E, Djohan V, Vanga-BossonH, Sylla-Thanon K, et al. (2011) Profil de résistance des Candida non albicans à Abidjan en 2011. Rev Bio-Afr 9: 25-31.

12. Offianan AT, Bonouma-Ira A, Angora KE, Vanga Bosson Henriette Sylla K, et al. (2016) Species identification of Candida isolates in various clinical specimens and their antifungal susceptibility patterns in Côte d'Ivoire. Afr J Microbiol Res 10(2): 66-72.

13. Kouadio Yapo CG, Aka NAD, Bonouman-Ira AV, Dou GSP, Sonan KHG, et al. (2020) Resistance of Candida albicans to antifungal drugs in Abidjan (Cote d'Ivoire). Afr J Microbiol Res 14(10): 572-578.

14. Whaley SG, Berkow EL, Rybak JM, Nishimoto AT, Barker KS, et al. (2017) Azole Antifungal Resistance in Candida albicans and Emerging Non-albicans Candida Species. Front Microbiol 7: 2173.

15. Zhang L, Wang H, Xiao M, Kudinha T, Mao LL, et al. (2014) The widely used ATB FUNGUS 3 automated readings in China and its misleading high MICs of Candida spp. to azoles: Challenges for developing countries' clinical microbiology labs. PLoS One 9: e114004.

16. Clinical and Laboratory Standards Institute (CLSI) (2020) Epidemiological Cutoff Values for Antifungal Susceptibility Testing. $3^{\text {rd }}$ (Edn.), CLSI supplement M59 Clinical and Laboratory Standards Institute, 950 West Valley Road, Suite 2500, Wayne, Pennsylvania 19087, USA.

17. Clinical and Laboratory Standards Institute (2008) Reference method for broth dilution antifungal susceptibility testing of yeasts; Approved standard, $3^{\text {rd }}$ (Edn.), M27-A3. Clinical and Laboratory Standards Institute,Wayne, PA 19087, USA.

18. Badiane AS, Diongue K, Sène A, Cheikh Seck M, Alpha 


\section{Open Access Journal of Mycology \& Mycological Sciences}

Diallo M, et al. (2021) Identification of Candida Species Circulating in Dakar using Multiplex Nested PCR. J Mycol Mycological Sci 4(1): 000140.

19. Hazirolan G, Altun HU, Gumral R, Gursoy NC, Otlu B, et al. (2017) Prevalence of Candida africana and Candida dubliniensis, in vulvovaginal candidiasis: first Turkish Candida africana isolates from vulvovaginal candidiasis. J Mycol Med 27(3): 376-381.

20. Seyoum E, Bitew A, Mihret A (2020) Distribution of Candida albicans and non-albicans Candida species isolated in different clinical samples and their in vitro antifungal suscetibity profile in Ethiopia. BMC Infect Dis 20(1): 231.

21. Rezaei Matehkolaei A, Shafiei S, Zarei-Mahmoudabadi A (2016) Isolation, molecular identification, and antifungal susceptibility profiles of vaginal isolates of Candida species. Iran J Microbiol 8(6): 410-417.

22. Shokoohi G, Rasekh-Jahromi A, Solhjoo K, Hasannezhad A, Nouripour-Sisakht S, et al. (2020) characterization and antifungal susceptibility of Candida species isolated from vulvovaginitis in Jahrom City, south of Iran. Jundishapur J Microbiol 13(10): e106825.

23. Bignoumba $M$, Onanga R, Bivigou Mboumba B, Gafou A, Mouanga Ndzime Y, etal. (2019) Vulvovaginal candidiasis among symptomatic women of childbearing age attended at a medical analysis Laboratory in Franceville, Gabon. J Mycol Med 29(4): 317-319.

24. Rosati D, Bruno M, Jaeger M, Ten Oever J, Netea MG (2020) Recurrent vulvovaginal candidiasis: An immunological perspective. Microorganisms 8(2): 144.

25. Waikhom SD, Afeke I, Kwawu GS, Mbroh HK, Osei GY, et al. (2020) Prevalence of vulvovaginal candidiasis among pregnant women in the ho municipality, Ghana: species identification and antifungal susceptibility of Candida isolates. BMC Pregnancy Childbirth. 20(1): 266.

26. Khan M, Ahmed J, Gul A, Ikram A, Lalani FK (2018) Antifungal susceptibility testing of vulvovaginal Candida species among women attending antenatal clinic in tertiary care hospitals of Peshawar. Infect Drug Resist 11: 447-456.

27. Hashemi SE, Shokohi T, Abastabar M, Aslani N, Ghadamzadeh M, et al (2019) Species distribution and susceptibility profiles of Candida species isolated from vulvovaginal candidiasis, emergence of $\mathrm{C}$. lusitaniae. Curr Med Mycol 5(4): 26-34.

28. Zhang W, Song X, Wu H, Zheng R (2019) Epidemiology, risk factors and outcomes of Candida albicans vs. nonalbicans candidaemia in adult patients in Northeast China. Epidemiol Infect147: e277.

29. Tsui C, Kong EF, Jabra-Rizk MA (2016) Pathogenesis of Candida albicans biofilm. Pathog Dis 74(4): ftw018.

30. Henriques M, Silva S (2021) Candida Albicans Virulence Factors and Its Pathogenicity. Microorganisms 9(4): 704.

31. Pfaller MA, Castanheira M, Messer SA, Moet GJ, Jones RN (2010) Variation in Candida spp. distribution and antifungal resistance rates among bloodstream infection isolates by patient age: report from the SENTRY Antimicrobial Surveillance Program (2008-2009). Diagn Microbiol Infect Dis 68(3): 278-283.

32. Africa CWJ and Dos Abrantes PMS (2017) Candida antifungal drug resistance in sub-Saharan African populations: A systematic review. F1000Research 5: 2832.

33. Flowers SA, Colón B, Whaley SG, Schuler MA, Rogers PD (2015) Contribution of clinically derived mutations in ERG11 to azole resistance in Candida albicans. Antimicrob Agents Chemother 59(1): 450-460.

34. Nweze EI, Ogbonnaya UL (2011) Oral Candida isolates among HIV-infected subjects in Nigeria. J Microbiol Immunol Infect 44(3): 172-177.

35. Feglo PK, Narkwa P (2012) Prevalence and antifungal susceptibility patterns of yeast isolates at the Komfo Anokye Teaching Hospital (KATH), Kumasi, Ghana. British Microbiol Res J 2(1): 10-22.

36. Dos Santos Abrantes PM, McArthur CP, Africa CWJ (2014) Multi-drug resistant oral Candida species isolated from HIV-positive patients in South Africa and Cameroon. Diagn Microbiol Infect Dis 79(2): 222-227.

37. Mulu A, Kassu A, Anagaw B, Beyene Moges, Aschalew Gelaw, et al. (2013) Frequent detection of 'azole' resistant Candida species among late presenting AIDS patients in northwest Ethiopia. BMC Infect Dis 13: 82. 